\title{
LOS LIBROS DE TEXTO Y LOS FUTUROS PROFESORES DE FÍSICA
}

\section{Textbooks and future Physics teachers}

\author{
Alejandro Parrella \\ Consejo de Formación en Educación. \\ Centro Regional de Profesores del Este, Maldonado, Uruguay. \\ ORCID http://orcid.org/0000-0002-5626-6057 \\ alejandroparrella@gmail.com
}

Recibido 1 de abril 2020

Aceptado 10 de junio 2020

\section{Resumen}

Los libros de texto son estructurantes del curriculum. Su muy escaso uso, a pesar de los diversos impulsos oficiales, genera inconvenientes que se consolidan conforme pasan las generaciones. Esta situación motivó la realización de este trabajo, que en su primera parte repasa algunas posturas sobre el libro de texto. En una segunda parte se presentan los resultados de indagaciones realizadas con alumnos de profesorado acerca de cuáles habían sido sus libros de Física de referencia durante su pasaje por secundaria. Por último, se plantea una idea para poder interpretar y encausar algunas de las críticas al uso del texto, de modo de focalizarse en aprovechar los beneficios de su utilización.

Palabras clave: Libros de textos, Estudiantes, Física

\begin{abstract}
Textbooks structure the curriculum. Its very little use, despite the various official impulses, generates inconveniences that become consolidated as the generations pass. This situation motivated doing this work, which in its first part reviews some positions about the textbook. In a second part, research results made with the teaching students about what Physics books were their reference during their passage through secondary school are presented. Finally, an idea is presented to be able to interpret and prosecute some of the criticisms of the use of the text, in order to focus on using the benefits of its use.

Keywords: Textbooks, Students, Physics
\end{abstract}




\section{Introducción}

Dos años consecutivos se indagó entre estudiantes de primer año del profesorado de Física acerca de cuáles habían sido sus libros de Física de referencia durante la educación secundaria, o cuál era el libro de Física que más les había impactado o incidido en su gusto por la asignatura. Lo llamativo de las respuestas es que eran muy pocos los que habían tomado contacto con un libro de texto de Física durante esa etapa de formación, y menos aún los que estudiaban sistemáticamente de ese texto. Por tanto, dos años seguidos aspirantes a profesores, de muy diversas edades y orígenes geográficos y con diversidad de biografías escolares, manifestaron que su relación con los textos de Física fue casi nula durante su pasaje por el liceo. Se está frente a un problema, porque los libros de texto son estructurantes del curriculum. Son un apoyo imprescindible para la tarea docente y para el buen desempeño del estudiante.

Hay voces contrarias a la utilización del libro de texto. Hay razones económicas, ideológicas y curriculares. Es así que en la enseñanza secundaria del Uruguay del siglo XXI es muy escasa la utilización de los textos, aunque haya habido por lo menos dos grandes impulsos oficiales. Entre 1995 y 2000 con la reforma del ciclo básico de secundaria se estableció que todos los alumnos recibirían un libro de texto por materia ${ }^{1}$ a principios de año y lo devolverían al finalizarlo. Más acá en el tiempo, con la creación de la Biblioteca Ceibal todos tienen acceso prácticamente ilimitado a la consulta electrónica gratuita de los textos para las distintas asignaturas. Aún con esas coyunturas, donde hubo y hay posibilidades de uso de libros de texto para los cursos de enseñanza secundaria, no se hace extensiva su utilización. Ya son varias generaciones que no estudian en libros de texto. Muchos de los profesores de hoy, cuando eran estudiantes en el secundario no convivían con los textos.

\section{Usar libros de texto}

Existen diversas definciones sobre lo que es un libro de texto. En este caso, se recupera la de UNESCO (2009, p. 14). Allí el libro de texto se define como "el medio de aprendizaje básico, compuesto por texto y/o imágenes, diseñado para producir un conjunto de resultados educativos" ${ }^{2}$. Luego se complementa o se explica esa primera definición, haciendo referencias a que un texto "reseña, estructura y hace accesible el estado del conocimiento de una asignatura dada" [ ...] "para presentar los cimientos del aprendizaje estándar y de la cultura compartida. Por lo tanto transmite el capital cultural de la sociedad a los ciudadanos más jóvenes”3.

1 Matemáticas, Idioma Español, Ciencias Naturales y Ciencias Sociales.

2 Traducción propia, parcial de la definición original: "Textbook: The core learning medium composed of text and/or images designed to bring about a specific set of educational outcomes; traditionally a printed and bound book including illustrations and instructions for facilitating sequences of learning activities".

3 Traducción propia, parcial del párrafo: “A textbook -usually consisting of text and/or illustrations- reviews, structures and renders accessible the state of knowledge in a given subject for a given age group in order to lay the foundations for standard learning and a shared culture. It thus transmits a society's cultural capital to its youngest citizens at a particular moment". 
Esta definición incluye parte de la función principal de la escuela: la transmisión cultural.

En este marco se ha generado un debate recurrente: ¿Hay que usar o no usar libros de texto para la enseñanza? En este trabajo se repasarán los argumentos a favor de su uso, luego se reseñan investigaciones sobre los beneficios de su utilización, y posteriormente se listan argumentos en contra, donde se establece una idea de postura docente que resuelve e integra las críticas.

Dentro de los argumentos a favor del uso, se indica que contienen (y se transforman en) el esqueleto de los cursos. Son vertebradores, en tanto como indica la UNESCO "reseña, estructura y hace accesible el estado de conocimiento de una asignatura dada". La ausencia de textos implica para el estudiante desconocer la estructura. No basta con conocer la lista de temas del curso, pues es el texto el que le da sentido a ese conjunto. Otro argumento es que el libro de texto es un apoyo importante a la labor de los docentes nuevos. La relación entre el docente y el texto que se propone para que los alumnos sigan el curso es un elemento crucial, y será clave en la resolución e integración de las críticas a su uso. En otro orden, la UNESCO indica que es posible aprovechar al libro de texto en tanto promotor de valores y comportamientos. A pesar de ser objeto de controversias, se acepta que cumplen un rol que trasciende a su contenido, transmitiendo modelos de comportamiento social, normas y valores. "Los textos son entonces una herramienta tanto para la educación y para el cambio social”. UNESCO (2009, p.12). Pueden ser el lugar donde reforzar y amplificar la política de defensa de los derechos de las personas, siendo que en algunos lugares no solo es el primer libro sino el único al que un joven llega a acceder. En ese mismo sentido, en la página web de la UNESCO ${ }^{4}$ se indica que: "La preparación de libros de texto de calidad contribuye a la aplicación de numerosos instrumentos internacionales ratificados por los diferentes gobiernos con miras a garantizar la libertad, la igualdad y la no discriminación". Como ejemplos de las posibilidades de brindan los libros de texto para incluir temáticas relacionadas a la libertad, igualdad y no discriminación se adjunta la tabla $1^{5}$ donde se aprecia la evolución intencional de la inclusión de esas temáticas en diferentes lugares.

Tabla 1

Comparación de menciones sobre los derechos humanos en libros de texto.

\begin{tabular}{cccc} 
Tema & Zona geográfica & $\begin{array}{c}\text { Época previa } \\
\text { (\% de menciones) }\end{array}$ & $\begin{array}{c}\text { Época a comparar } \\
\text { (\% de menciones) }\end{array}$ \\
\hline Derechos humanos & África subsahariana & 1970's (28\%) & 2000's (50\%) \\
\hline Derechos humanos & $\begin{array}{c}\text { Norte de África/ } \\
\text { Cercano oriente }\end{array}$ & 1970's (14\%) & 2000's (36\%) \\
\hline Derechos de discapacitados & -- & 1970 's (2\%) & 2000's (9\%) \\
\hline $\begin{array}{c}\text { Derechos de minorías étnicas, } \\
\text { culturales y religiosas }\end{array}$ & -- & 1970 's (13\%) & 2000's (28\%) \\
\hline
\end{tabular}

4 https://es.unesco.org/themes/ecm/libros-texto

5 Tabla elaborada en base a datos de blogconlicencia.com/importancia-necesidad-de-loslibros-de-texto/ 
De hecho, la elaboración y distribución de libros de texto que reflejen un curriculum que ponga en práctica los derechos humanos son parte de las directivas para la promoción de los mismos, elaborada por la UNESCO en el año 2003 (UNESCO 2009, p.11). En algunos lugares, el libro de texto es el único contacto de muchas familias con un libro. Según UNESCO (2009)

Para muchos alumnos y sus familias, los libros de texto son la única introducción al mundo escrito en los hogares, donde no hay libros, por la razón que sea: la cultura, problemas de distribución o entrega, costos, etc. Porque los niños más pobres no tienen acceso a material didáctico, a menudo se encuentran con mayores dificultades de aprendizaje. De ese modo, el acceso a los textos es usualmente una de las primeras recomendaciones de política educativa. ${ }^{6}$ (p. 15)

De ese mismo modo, pueden ser revolucionarios en catalizar cambios grandes en la didáctica de la disciplina. En el caso de Física, puede pensarse en aquellos textos que giran alrededor del tratamiento de ideas previas, que redimensionen el peso de las diferentes temáticas de la Física, u otros que promueven el modelado computacional. Si no existieran las innovaciones a través de los textos, sería mucho más lento e improbable el aterrizaje a las aulas de los conocimientos generados a partir de las investigaciones didácticas o los cambios en la concepción epistemológica de la propia disciplina. De forma análoga a lo referido por UNESCO sobre el hecho de que en algunas casas el único libro que entraba relativo a los derechos humanos era el libro de texto, podemos decir también que el texto de Física es el único libro de Física que hay en algunas casas. Esa es también una función fundamental del texto, ser el único vehículo de algunas ramas del conocimiento.

Hay también estudios (Textbook Challenge`) sobre la relación entre el uso de libros de texto en Matemáticas y la ubicación del país en el ranking educativo de la OCDE. En la tabla $2^{8}$ se ponen tres ejemplos donde se observa que en los países donde el uso es más intensivo, se tienen mejores resultados académicos:

Tabla 2

Comparación entre posición en OCDE y el uso de libros de texto.

\begin{tabular}{cccc}
$\begin{array}{c}\text { Ubicación } \\
\text { OCDE 2015 }\end{array}$ & País & $\begin{array}{c}\text { Porcentaje de docentes que usan libro de texto en } \\
\text { Matemáticas y en ciencias }\end{array}$ \\
\hline 1 & Singapur & Matemáticas $70 \%$ & Ciencias $68 \%$ \\
\hline 6 & Finlandia & Matemáticas $95 \%$ & Ciencias $94 \%$ \\
\hline 20 & Reino Unido & Matemáticas $10 \%$ & Ciencias $4 \%$ \\
\hline
\end{tabular}

$6 \quad$ Traducción propia de "For many pupils and their families, textbooks are the only introduction to the written word in homes where there are no books, whatever the reason: the culture, distribution or supply problems, cost, etc. Because the poorest children do not have access to teaching aids, they often face the greatest difficulties in learning. Thus access to textbooks is usually one of the first recommendations made by policy-makers."

7 http://www.textbookchallenge.uk/evidence.html

8 Tabla de elaboración propia a partir de la información de http://www.textbookchallenge. uk/evidence.html 
El mismo informe indica que se encuentra que el poco uso de los textos en Inglaterra es uno de los factores que explican la baja puntuación en Matemáticas, e indica que ese poco uso tiene raíces en una hostilidad ideológica hacia los textos. Luego continúa indicando características ya mencionadas, como que el texto fomenta la claridad de los conceptos clave y brinda claridad en el progreso de los aprendizajes. Otra observación es que en un país como Finlandia, donde la exigencia en la formación docente es comparativamente muy alta, hay un uso muy intensivo de los libros de texto (en Ciencias es un 94\%).

Otras evidencias cuantitativas relativas al uso de libros de texto en países en desarrollo se pueden encontrar en el trabajo de UNESCO (2016). En Ghana, la mejora en la disponibilidad del libro de texto generó una mejora en la evaluación de Matemáticas e Inglés entre 1988 y 2003. En Sudáfrica, ese mismo factor generó una mejora en la evaluación de la lectura. En ese mismo sentido "proporcionar un libro de texto a cada alumno de un aula aumentaba las puntuaciones relativas a la alfabetización entre un 5\% y un 20\%”. (UNESCO 2016, 4)

\section{Relato hegemónico o vertebrador del curso}

A pesar de la evidencia descrita en el apartado anterior, sigue habiendo argumentos en contra del libro de texto. Provienen de varios orígenes, grupos de padres, psicólogos e incluso algunos pedagogos. Los argumentos que se plantean también son de diversa índole. En este apartado, se analizarán esos argumentos y se pondrá en juego una hipótesis de postura docente que permite resignificar esas posiciones contrarias.

Algunos de los argumentos contra el libro de texto es que no desarrollan competencias de lenguaje y además favorecen el aprendizaje memorístico, y que son una limitante absurda del conocimiento. Ahora bien, esto puede suceder en el aula cuando el docente toma decisiones didácticas que favorezcan ese tipo de trabajo. Son decisiones docentes que no tienen que ver con el uso o no del libro de texto, sino con el planteo didáctico general. Aquí se propondrá categorizar en dos grandes grupos el posicionamiento de los docentes frente al libro de texto. A grandes rasgos, hay docentes toman al libro de texto como vertebrador del curso y hay otros que lo asumen como relato hegemónico. Los primeros organizan el curso junto con el libro de texto, tomándolo como apoyo central, dejando para sí las decisiones didácticas. Los segundos toman el texto como relato hegemónico y siguen a pie juntillas las actividades planteadas en el orden preestablecido, quizá asumiendo en forma literal las sugerencias del manual para el docente que tienen muchos de los textos. En este segundo caso, el docente se parece más a un instructor que a un profesor. Las críticas al uso del libro de texto apuntan a quienes lo toman como relato hegemónico del curso, pero no tienen en cuenta que están criticando el medio (el texto) y no la forma en que este es utilizado.

En la siguiente tabla se plantean algunas características que tienen los planteos didácticos de quienes toman cada una de esas posturas 
Tabla 3

Comparación de posturas docentes frente al libro de texto.

Postura: "texto como vertebrador"

La lectura del libro es principalmente domiciliaria, o bien se relee algún pasaje en el aula para ser analizado e interpretado.

Postura: "texto como relato hegemónico"

Se dicta la clase con el esquema del libro". La secuencia es: Introducción, Definición, Aplicación, Interpretación y Problematización

El docente genera preguntas para interpretar lo leído y para interpretar las imágenes (gráficas, infografías, etc) que aparecen en el libro.

Toma decisiones curriculares en base al argumento: "porque está en el libro".

Plantea las clases con el centro en el estudiante, pudiendo utilizar técnicas de aprendizaje activo, y usando el libro de texto como material de soporte por ejemplo para una flipped classroom.

La clase la organiza en torno al dispositivo didáctico que considera más pertinente en función del objetivo.

Planifica mayormente clases expositivas con el orden indicado en el texto.

No sugiere complementar lo aprendido con otras lecturas, actividades, simuladores o videos, a menos que el propio texto lo sugiera.

El texto es el inicio del camino
particular de cada estudiante en el estudio
de los contenidos a tratar.

* Nota: Para una descripción detallada, ver Jimenez Valladares y Perales Palacios (2001).

Retomando los primeros argumentos reseñados, favorecer el aprendizaje memorístico y limitar el conocimiento al libro de texto son derivaciones de tomar al libro de texto como relato hegemónico, y que además el libro en cuestión sea solo una colección de conocimientos. Si se concibe al texto como vertebrador del curso suceden otras cosas, como lo indica Pingel en el trabajo para la UNESCO (2010),

Las clases en las que los alumnos son puestos en el foco de la instrucción, están reemplanzando a las tradicionales, centradas en el docente. La variedad de materiales y métodos dados por los textos son usados para inspirar a los alumnos a preguntarse y a explorar caminos para responder esas preguntas $^{9}$. (p. 49)

En otro de los argumentos en contra del uso de los libros de texto se sostiene que están diseñados para dictar clases magistrales y para promover el trabajo individual. Sumado a estos, también se argumenta que en los libros se presenta el conocimiento como algo inamovible, sin evolución. Estos nuevos argumentos también caen dentro de lo ya discutido. Los buenos textos y los docentes profesionales no propician esas conductas. Se observa que se argumenta contra los libros de texto mirando las malas prácticas que se hacen con ellos. En otro pasaje, Pingel (2010, p.37) indica que "Los textos como herramientas educacionales

$9 \quad$ Traducción propia de: "Lessons in which the pupils are placed in the spotlight of the instruction procedure are replacing the traditional teacher-centric classroom. The various materials and methods provided by textbooks are used to inspire pupils to ask questions and to explore ways in which these questions may be answered". 
ofrecen grandes oportunidades y pueden ir más allá de simplemente transmitir hechos." 10

Otros argumentos refieren a la idea que sin usar libros de textos el alumno irá a buscar a más de una fuente, e inclusive a las fuentes originales. Es empíricamente demostrable que por sí mismo el alumno no busca en una variedad de fuentes para analizar, que esa habilidad debe ser promovida por el docente, y que el libro de texto no es un obstáculo siempre que la postura docente no sea tomarlo como relato hegemónico.

Otros sostienen argumentos respecto a que son peligrosos para la higiene postural de los niños, pues al cargarlos en la mochila generan mucho peso, y otros que se trata de un despilfarro económico. Ambos argumentos no son de recibo, el primero porque hay diversas maneras de usar textos sin tener que cargarlos siempre, todos los libros, todos los días. El segundo, porque hay muchos ejemplos de políticas educativas nacionales o regionales que procuran subvencionar el costo de los textos.

Un argumento falaz, es aquel que manifiesta que los textos está hechos para alumnos homogéneos. Para empezar, cualquier texto escrito manifiesta una determinada idea, de modo que quienes sostienen este argumento no toman en cuenta que el proceso de lectura es una interacción entre el lector y el texto. Además, en el caso del libro de texto, está mediado también por el accionar docente. Pingel (2010) sostiene que tradicionalmente se hacían las revisiones a los libros para rectificar errores u omisiones, y que se asumía que "si el contenido de un texto no era ambiguo, todos los alumnos lo entenderían de la misma manera. Un número creciente de los alumnos de hoy, sin embargo, no leen los textos de la forma oficial" (si alguna vez eso fue asi) $)^{11}$ (p. 54)

Otros cuestionamientos al libro de texto refieren a la incidencia sobre los docentes. Quienes no recomiendan el uso de los libros de texto como herramienta para la enseñanza sostienen que limita la creatividad del docente. Si se mira el problema de la creatividad a la luz de las dos grandes posturas relatadas anteriormente, veremos que no es el libro en tanto herramienta el que provoca esa consecuencia, sino que es el uso que se le da a la misma. Según Sikorova (2011)

Los docentes buscan a los textos para informarse sobre asuntos de la asignatura; especialmente como está estructurada, si se presenta en detalles o no y cuál es la secuencia de los temas. Más aún, al menos algunos docentes confían en los textos cuando preparan las clases; siguen explícita o implícitamente la metodología contenida en los textos ${ }^{12}$. (p. 5)

$10 \quad$ Traducción propia de: "Textbooks as educational tools offer greater opportunities and can do much more than merely convey facts".

11 Traducción propia de: "If the content of a textbook is unambiguous, all students would understood it in the same way. For a growing number of today's pupils, however, texts are no longer read in such an authoritative way (if they ever have been)".

12 Traducción propia de: "Teachers search textbooks for information about subject matter: especially how it is structured, if it is presented in detail or not and what the sequence of topics is. Moreover, at least some teachers rely on textbooks when preparing and realising lessons; they follow the methodology explicitly or implicitly contained in textbooks". 
Obsérvese que en este párrafo se hacen mención a las dos grandes posturas antes mencionadas. Quienes lo toman como relato hegemónico son los docentes que luego replican hasta la metodología presentada en los textos. El reto de los docentes es aprovechar la función vertebradora fundamental del texto manteniendo para sí las decisiones didácticas pertinentes al aula, pero nunca renegar del libro de texto excluyéndolo del aula.

\section{¿Qué libros eligen los estudiantes de profesorado?}

Se realizó dos años consecutivos una indagación a alumnos de primer año de profesorado de Física, en la que se preguntaba cuáles habían sido sus libros de Física de referencia durante la educación secundaria, o cuál era el libro de Física que más les había impactado o incidido en su gusto por la asignatura, y que explicaran las razones de su elección. Se hizo en las primeras semanas del curso, y a partir de las intervenciones de los estudiantes se buscaba responder: ¿Qué libros eligen? ¿Qué características tienen esos libros? ¿Cuáles son las razones que esgrimen para elegirlos? ¿Eligen entre muchos libros o entre pocos? ¿Conocen muchos libros o textos de Física? Las respuestas brindadas por los estudiantes fueron previsiblemente dispares. Por lo tanto se procedió a realizar una categorización de esas respuestas de acuerdo al tipo de libro que recomendaron. Se encontraron cinco tipos de libros, que se resumen en la siguiente tabla:

Tabla 4

Categorías de los libros recomendados por los estudiantes

Categoría de libro recomendado por el estudiante

Porcentaje

\begin{tabular}{cc} 
Libro de divulgación & $21 \%$ \\
\hline Texto de Física usado en otro curso terciario o técnico & $19 \%$ \\
\hline Libro de curso usado en paralelo en el curso de Física 1 de profesorado & $19 \%$ \\
\hline "La Física entre nosotros” & $22 \%$ \\
\hline Otro texto usado en el liceo & $19 \%$ \\
\hline
\end{tabular}

Hay un grupo importante de alumnos (59\%, casi 3 de cada 5) que no asocian "texto de Física" a sus clases del liceo -las tres primeras categorías de la tabla-. Entre los que recomiendan el libro de texto que usan en el curso paralelo de Física 1, los testimonios incluyen frases como "Nunca tuve libros de referencia, ahora estoy leyendo Resnick", o "No tengo libro de Física de la época de secundaria” y a continuación recomienda el texto de Física Universitaria de Sears. Dentro de los que describen textos de Física usados en otros cursos terciarios, universitarios o técnicos, se encuentran casos donde se recomiendan manuales que no son específicos de Física, sino que son manuales técnicos como libros sobre capacitación en instalaciones eléctricas, de cuando esos estudiantes en particular cursaban esas carreras, y otro caso de libros sobre instalación de aire acondicionado que había leído cuando trabajaba en una empresa dedicada a ese rubro. "Es la biblia del aire acondicionado". También en ese grupo se encuentran los que asocian libros de divulgación, o libros que para el estudiante tienen un componente afectivo especial. Como ejemplo, se puede citar que aparece más 
de una vez "El Tao de la Física" - una de esas menciones la hace alguien por motivos religiosos, al definirse budista- y también aparece el reconocido bestseller de Stephen Hawking "Historia del tiempo". En cuanto a libros que tienen para el estudiante componentes afectivos, hay, por ejemplo, un testimonio que refiere a un libro de Física general de un autor español de mediados del siglo XX, que se lo regaló su madre y "lo había acompañado desde ciclo básico". U otro caso en que recomienda un libro de "Física y química" porque le tiene estima dado que se lo regaló su abuela -era de ella- cuando el estudiante estaba en los primeros años del liceo. Todos estos testimonios son parte de ese $59 \%$ de alumnos que no asocian un libro de Física a las clases del liceo.

Luego están el otro $41 \%$ de respuestas que sí lo hacen, donde se destacan (22\%) las menciones al texto "La física entre nosotros" (de Marcelo Szwarcfiter y Ernesto Egaña, Ed. Monteverde). Esa serie de libros se editaron a principios de los 2000, popularizándose rápidamente entre los estudiantes por ser en su época los que se adaptaban a los programas vigentes. Además contenían una serie de ejercicios que servían como práctica para las evaluaciones ${ }^{13}$. Ahora bien, llama la atención que entre los argumentos esgrimidos por los estudiantes, no se evidencia que hayan sido el eje de los cursos dictados por el docente, sino que los propios estudiantes accedieron a ese material como soporte para la preparación de sus parciales o sus exámenes. A modo de ejemplo, un testimonio indica que "Trabajábamos con fotocopias en clase. Yo igual miré algunos libros”, o "Básicamente trabajábamos con repartidos" y los alumnos indican que fueron ellos quienes se acercaron al libro, o como el caso de otro testimonio que indica que "lo encontró para repasar". También hay testimonios de alumnos que lo usaron como preparación del examen libre de Física. Las opiniones vertidas sobre el libro giran alrededor de la claridad de los conceptos así como de la disponibilidad de ejercicios y ejemplos resueltos. No se desprende de los testimonios que ese libro haya sido mayoritariamente usado por el docente para estructurar el curso, o que en clase se tuviera como referencia permanente. Fueron los estudiantes quienes se acercaban por su cuenta al libro. Esto evidencia, una vez más, la necesidad de que exista un texto que apoye el estudio de los alumnos. Es llamativo el contraste entre estos testimonios y lo expresado en los programas actuales oficiales del Consejo de Educación Secundaria $(2006,19)$ : "Se considera pertinente que el docente adopte un texto como base para el desarrollo del curso, que puede o no ser elegido entre los incluidos en esta bibliografía”. "Adopte un texto" está resaltado en negritas en el documento original. En cuanto al último grupo, de quienes recordaban otro libro, la mayoría de ellos eran mayores de 30 años, es decir que son alumnos que promedian más edad que la media del grupo, lo que implica que pertenecen a generaciones de estudiantes que tenían, en general, mayor vínculo con los libros de texto.

\section{Enseñar usando textos}

Luego de la descripción anterior se establece un panorama problemático: habiendo evidencias de la importancia del uso de textos para la mejora de los aprendizajes de los estudiantes, se cuenta con una población de aspirantes a profesores

13 En esa época el examen final de Física en los dos últimos años de bachillerato era obligatorio. 
que no experimentaron estudiar con un libro de texto en secundaria. Por tanto, se hace necesario establecer una estrategia que les permita a estos candidatos a profesores experimentar el uso del texto para luego poder reflexionar sobre las formas en que un docente debe incluir el texto en sus clases. Es decir, a nivel general, estamos un paso por detrás. Lo primero es constatar si los estudiantes se adaptan rápidamente a estudiar de un texto, si conocen las partes del texto. Para eso, es importante rescatar los testimonios relacionados con el curso de Física 1 de primer año de profesorado. Es allí donde se debe trabajar con un texto y explícitamente desarrollar estrategias de máximo aprovechamiento. En ese sentido, también es un desafío para los docentes de Física de formación docente predicar con el ejemplo para mostrar como se enseña con libros de texto.

Después de tanto tiempo sin enseñar masivamente con libros de texto en educación media, se está en la encrucijada de pensar ¿Qué prácticas docentes permiten aprovechar las ventajas de enseñar con un libro de texto como estructurante? ¿Cómo generar actividades que no conviertan al libro en el relato hegemónico para no propiciar los otros inconvenientes no deseados? En palabras de Pingel (2010) algunas de las preguntas que deben guiar las indagaciones serían

¿Cómo los usan los docentes y los estudiantes?, ¿Los textos son el foco de la enseñanza en el aula? ¿Los alumnos aprenden partes del texto de memoria? ¿Los docentes deben seguir el texto capítulo a capitulo o son libres de elegir lo que coincide con los intereses y deseos de los estudiantes? ${ }^{24}$ (p. 46)

En ese sentido el autor insiste en que aún se tiene poco conocimiento del rol que juegan los textos en el aula, existiendo una ausencia de estudios internacionales comparativos. Lo que se puede afirmar es acerca del rol que juegan a la hora de que el docente prepara y estructura sus clases, pero no sobre la forma en que se usa durante el tiempo de aula. En suma, además de la coyuntura desfavorable descrita anteriormente, queda allí también temática para investigar.

\section{Conclusiones}

La primera conclusión es que los libros de texto son necesarios. De todos los argumentos esgrimidos, se destaca el referido a su carácter estructurante. Banderas (2017) lo describe de la siguiente manera:

Cualquiera que haya entrado en un aula se habrá dado cuenta de que los alumnos necesitan tener muy clara la estructura de la sesión, saber qué deben estudiar y qué deben hacer y de qué modo. Si los libros de texto se sustituyen por materiales sin un orden claro en su metodología, los alumnos acaban perdiéndose, algo que influye en la predisposición de estos hacia la asignatura.

14 Traducción propia de "How do teachers and students use them? Are textbooks at the focus of classroom teaching? Do pupils learn parts of the text by heart? Do teachers have to follow the text chapter by chapter or are they free to choose whatever coincides with the students' interests and desires?” 
Los estudiantes necesitan conocer la ruta por la que se va a transitar en la clase. También es claro que transitar por esa ruta de modo monótono y previsible, convirtiendo al libro de texto en parte de un dogma, trae consecuencias educativas no deseadas. Por tanto, la pregunta que debe guiar la investigación y la reflexión es: ¿Cómo se debe posicionar un docente frente a un libro de texto?.

En ese sentido, lo que se propone en este artículo es reconocer que algunos docentes pueden tomar al libro de texto como vertebrador del curso y otros lo asumen como relato hegemónico. En esta segunda postura, el docente se posiciona como instructor en lugar de profesor. Por otra parte, hay otro enfoque más a tener en cuenta a la hora de realizar indagaciones sobre los libros de texto, y tiene que ver con los procesos de redacción y producción de los mismos. Un buen libro de texto es producto de un largo camino, que no es lineal sino espiralado, que debe implicar un proceso de evaluación y monitoreo permanente. En UNESCO (2005, p.11) se indica que deben ser producto de largos procesos de desarrollo curricular, con permanente evaluación y revisión. En Uruguay los programas de estudios y su bibliografía recomendada suelen ser establecidos en un momento dado, y luego transformados por otro programa varios años después, a veces con cambios radicales. Lo que propone la UNESCO es hacerlo de modo que los procesos permanentes de reformas sean vistos de forma natural. Asimismo, entre otros aspectos, se plantea que en los textos se deben establecer objetivos claros y evaluables, donde se tengan en cuenta múltiples perspectivas, diversos estilos de aprendizaje, y además, tanto los contenidos, como las habilidades y las actitudes. Esto hace pensar que para los cursos de Física en Uruguay hace falta un largo camino, no solo en lo relativo a la producción de libros de texto, sino en la reflexión continua sobre el curriculum.

\section{Bibliografía}

Banderas Navarro, Néstor (2017), “Libros de texto, sí o no", Recuperado de: https://www.xarxatic.com/libros-de-texto-si-o-no/.

Consejo de Educación Secundaria (2006), "Programa de física segundo año bachillerato opción biológico y científico". Recuperado de https://www.ces. edu.uy/files/Planes\%20y\%20programas/Ref\%202006\%20Bach/5to\%20 biologico/fisica biologico.pdf.

Jimenez Valladares y Perales Palacios (2001), "Aplicación del análisis secuencial al estudio del texto escrito e ilustraciones de los libros de física y química de la ESO” Revista Enseñanza de las ciencias, 2001, 19 (1), 3-19.

Pingel, Falk (2010) "UNESCO guidebook on textbook research and textbook revision" 2nd revised and updated edition, Paris/Braunschweig, UNESCO

Sikorova, Zuzana (2011), "The role of textbooks in lower secondary schools in the Czech Republic” IARTEM e-Journal 2011 Volume 4 No 2. 1-22.

UNESCO, (2005), "A comprehensive strategy for textbooks and learning materials".

Recuperado de: https://unesdoc.unesco.org/in/rest/annotationSVC/ DownloadWatermarkedAttachment/attach import 5e45ac40-fb0e-4293b0f9-d8432310d001? = 143736engb.pdf.

UNESCO, (2009) "Promoting gender equality through textbooks. A methodological guide". Recuperado de https://unesdoc.unesco.org/in/documentViewer. 
xhtml?v $=2.1 .196 \& \mathrm{id}=\mathrm{p}:$ :usmarcdef 0000158897 eng\&file $=/$ in $/$ rest/annotationSVC/DownloadWatermarkedAttachment/attach import 44cd0880-b1a7-4bae-be22-825007d413d2\%3F \%3D158897eng. pdf\&locale $=$ es\&multi $=$ true\&ark $=/$ ark: $/ 48223 /$ pf0000158897 eng $/$ PDF/158897eng.pdf\#\%5B\%7B\%22num\%22\%3A68\%2C\%22gen\% 22\%3A 0\%7D\%2C\%7B\%22name $\% 22 \% 3 \mathrm{~A} \% 22 \mathrm{XYZ} \% 22 \% 7 \mathrm{D} \% 2 \mathrm{C}-$ $198 \% 2 \mathrm{C} 792 \% 2 \mathrm{C} 0 \% 5 \mathrm{D}$.

UNESCO, (2016), "Cada niño debería tener un libro de texto", Documento de política 23, Enero de 2016. Recuperado de https://unesdoc.unesco.org/ ark:/48223/pfo000243321 spa/PDF/243321spa.pdf.multi 